\title{
Cytokines in Systemic Lupus Erythematosus
}

\section{Citation}

Poole, Brian D., Timothy B. Niewold, George C. Tsokos, and Charles S. Via. 2010. Cytokines in systemic lupus erythematosus. Journal of Biomedicine and Biotechnology 2010: 735169.

\section{Published Version}

doi:10.1155/2010/735169

\section{Permanent link}

http://nrs.harvard.edu/urn-3:HUL.InstRepos:5136363

\section{Terms of Use}

This article was downloaded from Harvard University's DASH repository, and is made available under the terms and conditions applicable to Other Posted Material, as set forth at http:// nrs.harvard.edu/urn-3:HUL.InstRepos:dash.current.terms-of-use\#LAA

\section{Share Your Story}

The Harvard community has made this article openly available.

Please share how this access benefits you. Submit a story.

\section{Accessibility}




\title{
Cytokines in Systemic Lupus Erythematosus
}

\author{
Brian D. Poole, ${ }^{1}$ Timothy B. Niewold, ${ }^{2}$ George C. Tsokos, ${ }^{3}$ and Charles S. Via ${ }^{4}$ \\ ${ }^{1}$ Brigham Young University, Provo, UT 84606, USA \\ ${ }^{2}$ University of Chicago, Chicago, IL 60637-1546, USA \\ ${ }^{3}$ Harvard University, Cambridge, MA 02138, USA \\ ${ }^{4}$ Uniformed Services University of Health Sciences, Bethesda, MD 20814, USA
}

Correspondence should be addressed to Brian D. Poole, bpoole@gmail.com

Received 31 December 2010; Accepted 31 December 2010

Copyright (C) 2010 Brian D. Poole et al. This is an open access article distributed under the Creative Commons Attribution License, which permits unrestricted use, distribution, and reproduction in any medium, provided the original work is properly cited.

Systemic lupus erythematosus, or lupus, is a systemic autoimmune disease characterized by the production of autoantibodies against nuclear components. Symptoms of lupus are varied and range from mild arthritis to renal failure. The disease affects at least 5 million people worldwide. Despite substantial effort over many years, conclusive answers regarding the etiology, pathogenesis, and treatment of lupus have remained elusive. However, recent research, including genome-wide genetic and transcriptional analysis has revealed potential roles for many different factors. This understanding of the disease is beginning to bear fruit with the development of therapeutics for lupus.

With the BLyS inhibitor Belimumab poised to be the first treatment for lupus approved by the United States Food and Drug Administration in decades, the potential of cytokines in the realm of therapeutic targets for lupus is starting to be realized. These fascinating molecules regulate multiple facets of the immune system and, as such, have been extensively examined for a role in many different aspects of lupus etiology, pathogenesis, and regulation. Given their powerful abilities and the potential for straightforward inhibition by biological or other pharmacological agents, multiple cytokines may be future targets for the treatment of SLE. A discussion of therapeutic cytokine inhibition, especially targeting of interferon alpha, is included in this issue. Also included is an analysis of unintended consequences of such treatments, where targeting of a cytokine (TNF-alpha) to treat rheumatoid arthritis can accelerate loss of tolerance and lupus-like autoimmunity.

Cytokine dysregulation is likely to play a role in the loss of immune tolerance that leads to lupus and in the damage resulting from the disease. Excess interferon alpha and interferon alpha responsive gene expression have been identified as hallmarks of many cases of lupus. IL-10 and IL-21 are cytokines that show increased expression in lupus, and which regulate lymphocyte development and tolerance. Another cytokine, IL-17, is dysregulated in lupus enhancing the pathogenesis of the disease. These and other proinflammatory cytokines are likely to not only contribute to loss of tolerance and the symptoms associate with lupus, but they likely accelerate atherosclerosis in lupus patients. Other cytokines, such as IL-2, are underexpressed in lupus, with detrimental effects on immune tolerance and T-regulatory cell development. All of these roles for cytokines in lupus are discussed in this issue.

Through the use of whole-genome screening techniques and large study populations, understanding of the genetic components of lupus is rapidly progressing. As cutting-edge genetic research into the etiology of lupus progresses, cytokines are becoming increasingly identified as genetic risk factors. Many of the genes that are associated with risk for lupus are cytokines, regulators of cytokines, or downstream members of cytokine pathways. Examples of these factors that are associated with risk for lupus and are examined in this special issue include Interferon Alpha, Interferon Kappa, Monocyte Chemoattractant Protein, Adiponectin, IL-10, IL-21, and Phosphoinositide Kinase. These lupus-associated genes are likely to contribute to the etiology of lupus, and understanding their roles will aid in defining the pathways that lead to loss of immune tolerance.

This special issue contains work investigating many different facets of the relationships between cytokines and lupus, and includes the following.

The article by D. Y. H. Yap and K. N. Lai is a review discussing pathologically relevant cytokines ant potential therapeutic interventions. The paper by H.-M. Lee et al. 
comprises an overall review of the topic covering many cytokines and their regulation in lupus, focusing on those that may contribute to pathogenesis. The review by M. Tucci et al. tackles linking cytokines, $\mathrm{T}$ cells and kidney damage in lupus. The review article by C. C. Mok demonstrates the potential for cytokines and chemokines in evaluating kidney disease in lupus. H. Okamoto et al. have written a review evaluating the utility of cytokines as markers for neuropsychiatric disease in lupus. The review article by $\mathrm{C}$. López-Pedrera et al. discusses cytokines in cardiovascular disease and evaluating therapeutic options for dealing with these cytokines. The paper by T. Hayashi outlines the role of Th1/Th2 balance in lupus and strategies for regulating that balance therapeutically. The article by K. H. Yoon evaluates the calcineurin inhibitor tacrolimus as a therapeutic agent for lupus, focusing on the effects of this drug on cytokine production. The paper titled " $I L-17$ in systemic lupus erythematosus" by J. C. Crispín and G. C. Tsokos describes the cellular sources and role of IL-17 in lupus pathogenesis, especially in nephritic disease. A review by L. A. Lieberman and G. C. Tsokos revolves around the aberrant production of IL-2 and IL-2 family members in lupus. The paper titled "Interferon alpha in systemic lupus erythematosus" by T. B. Niewold et al. shows the multiple mechanisms through which interferon alpha contributes to lupus, as well as the clinical implications of this dysregulation. M. Sarra and G. Monteleone work supports a role for IL-21 in lupus pathogenesis.

"Anti-TNF- $\alpha$ therapies in systemic lupus erythematosus" by L.-J. Zhu et al. highlights the effects of anti-TNF alpha treatments on lupus and the role of TNF alpha in lupus and lupus-like disease. E. Kassi and P. Moutsatsou analyze in their review the potential role of cytokines in the increased risk of lupus for women. L. Dong et al. examine in their research article the correlation between lipid rafts, cytokine expression, and lupus. Keiko Yoshimoto et al. suggest in their research article an impairment in the regulation of TCR zeta in lupus. The article titled " $I L-10$ and $T N F \alpha$ genotypes in $S L E$ " by P. López et al. summarizes the involvement of IL10 and TNF $\alpha$ genetic variants on SLE etiology, and clinical relevance. W. L. Fang et al. analyze in their research article adiponectin alleles and their relationship with risk for lupus. In the research article by $\mathrm{P}$. Piotrowski et al., we see that they are clarifying and supporting a role for MCP1 polymorphisms in lupus risk. A. Kawasaki et al. confirm in their research article that TNFAIP3 is a risk factor for lupus. I. T. W. Harley et al. identify in their research article a novel single nucleotide polymorphism that is associated with risk for lupus in males. S. N. Kariuki et al., in their research article, highlight a functional consequence on the antibody profile of a promoter variant associated with risk for lupus. M. Zhao et al. have written a research article examining epigenetic factors on expression of important lupus-related cytokines. The paper "Cytokine-induced monocyte characteristics in SLE" by $Z$. Zhang et al. demonstrates epigenetic changes due to lupus cytokines.

Cytokine research holds tremendous promise for understanding and treating lupus. We are grateful to all those who contributed articles for this special issue and those who reviewed and in other ways contributed. We hope that this avenue of research will continue to be supported and be a benefit to the lives of those suffering with this complex and difficult disease.
Brian D. Poole

Timothy B. Niewold

George C. Tsokos

Charles S. Via 